\title{
Tinjauan Yuridis Sertifikat Kesehatan Sebagai Perlindungan Hukum Bagi Penerbang Sipil Di Indonesia
}

\author{
Benny Hosiana Tumbelaka, Agnes Widanti dan Tri Wahyu Murni \\ Benny_hosiana@gmail.com \\ Magister Hukum Kesehatan \\ Universitas Katolik Soegijapranata Semarang
}

\begin{abstract}
ABSTRAK
Penelitian ini meninjau secara yuridis akan keabsahan Sertifikat Kesehatan Penerbangan Sipil di Indonesia dalam kurun waktu, sejak diterbitkan sampai habis masa berlakunya.

Metode pendekatan yang dipergunakan adalah metode pendekatan yuridis normatif berdasarkan Undang Undang RI nomor 1 tahun 2009 tentang Penerbangan, dan Peraturan Pemerintah RI nomor 3 tahun 2001 tentang keamanan dan keselamatan Penerbangan beserta beserta Peraturan Pelaksanaan dari perundang undangan tersebut.

Hasil penelitian ini, bahwa regulasi bidang Keselamatan penerbangan yang berlaku di Indonesia tentang fungsi pengawasan memperoleh Sertifikat Kesehatan, khususnya pada Penerbang Sipil Airline Transport Pilot (Sertifikat Kesehatan kelas satu), telah sesuai dengan standar ICAO, yaitu Keputusan Direktur Jendral Perhubungan Udara Nomor: SKEP/62/V/2004 tentang Sertifikat Kesehatan Personil Penerbangan. Didapatkan juga bahwa langkah yang diambil agar Sertifikat Kesehatan Penerbang Sipil di Indonesia yang berlaku 6 bulan ke depan, belum ada, baik aturannya, mekanismenya bahkan SDM belum memadai secara kualitas dan kuantitas. Sehingga sertifikat tersebut belum dapat terjaga keabsahannya. Sedangkan Penerbang yang mendapatkan medical flexibility perlu dilindungi statusnya dengan Surat keputusan Menteri bagi Tim penilai kesehatan (Medical Asessor) dan Tim Pakar kesehatan Penerbangan (Aeromedical Consultation Service) yang merekomendasi kasus ini. Penerbang tersebut selain mengisi checklist, ia dijadwalkan secara tetap untuk memeriksakan kekurangannya dan melaporkan pada dokter penerbangan.
\end{abstract}

Sebagai saran dalam penelitian ini agar diusulkan kepada Menteri Perhubungan melalui Dirjen Perhubungan Udara beberapa hal, yaitu untuk mengeluarkan keputusan tentang tata kerja menjamin keabsahan Sertifikat Kesehatan Penerbang Sipil di Indonesia. Mengusulkan penambahan personil fungsional pada Pusat Kesehatan Penerbangan Sipil sehingga dapat melaksanakan tugas dan fungsinya sesuai Keputusan Menhub no. SK 38/OT 002/Phb.83 tentang organisasi dan tata kerja Balai Kesehatan Penerbangan Dirjen Perhubungan Udara. Dan agar setiap operator penerbangan harus mempunyai dokter penerbangan untuk menerima pendelegasian wewenang dalam pengawasan Penerbang di lapangan termasuk kasus medical flexibility. Mengusulkan agar menerbitkan Surat Keputusan Menteri untuk jabatan Medical Asessor, dan Aeromedical Consultation Service, yang berisi fungsi dan wewenangnya serta pengawakannya agar Penerbang yang mendapatkan medical flexibility terlindungi statusnya.

Kata kunci : Sertifikat Kesehatan Penerbang Indonesia, Keabsahan, Keamanan dan keselamatan penerbangan 


\section{PENDAHULUAN}

Pada tanggal 25 Juli 2006 kita mendengar berita seorang pilot maskapai penerbangan Indonesia, meninggal ketika akan menjalankan tugas terbang Bali - Adelaide via Melbourne. Menurut informasi, setelah penumpang boarding dan pintu pesawat ditutup almarhum memerlukan pertolongan gawat darurat. Tim medis bandara langsung mengadakan pertolongan dan membawa ke rumah sakit terdekat. Pada jam 01.35 pilot dinyatakan telah meninggal (Death on Arrival). Sejak tahun 1997 almarhum mempunyai masalah dengan kadar lemak. Pada 2006, dirawat karena stroke selama 3 hari dan almarhum tidak melaporkan diagnosa penyakit tersebut ke manajemen kesehatan maskapai penerbangannya sehingga ia tetap dapat melakukan tugas terbang.

Untuk mendapatkan pernyataan secara medis seorang Penerbang laik atau tidak laik dalam tugas terbang maka ia harus menjalani pemeriksaan kesehatan secara seksama dan bila dinyatakan lulus oleh Tim kesehatan, maka dikeluarkanlah sertifikat kesehatan tersebut ${ }^{1}$. Sertifikat ini berlaku untuk 6 bulan ke depan dan karena itu juga maka pemeriksaan dilakukan 6 bulan sekali ${ }^{2}$. Pemeriksaan ini penting bukan saja untuk mendeteksi risiko penyakit sebelum menjadi suatu bahaya dalam melaksanakan tugas terbang maupun kehidupan sehari hari, tetapi juga untuk perlindungan hukum bila terjadi hal hal yang tak diinginkan dalam menjalankan tugasnya.. Namun apakah dengan adanya sertifikat kesehatan tersebut maka status kesehatan si Penerbang terjamin sehat sampai 6 bulan ke depan? Dalam beberapa kasus dimana seorang Penerbang mengidap penyakit kronis (seperti Diabetes Mellitus, Hipertensi, dll) tapi penyakitnya masih terkontrol dan selama penyakitnya terkontrol, maka tidak mengakibatkan pengaruh buruk dalam tugasnya, sehingga ia masih dianggap laik untuk tugas terbang. Penerbang tersebut harus dibantu oleh dokter penerbangan agar kondisinya tetap terjaga dan tak mengganggu tugas terbangnya. Permasalahan pada kasus ini adalah :

a. Belum ada pengawasan terhadap Penerbang setelah Sertifikat Kesehatan dikeluarkan.

b. Belum ada aturan yang menyebutkan bahkan mengharuskan atau boleh dikatakan memaksa perusahaan agar menyiapkan petugas medis yang bertugas memonitor para Penerbang.

c. Belum seluruh Penerbang sadar untuk selalu melaporkan kondisinya sesaat sebelum terbang. Para Penerbang meyakini kariernya akan terganggu bila dilaporkan secara jujur yang tentunya mempunyai akibat berantai dengan pendapatan dan tunjangan yang didapatkan selama ini.

Apabila permasalahan tidak diselesaikan, maka Sertifikat Kesehatan (yang berlaku 6 bulan) yang diberikan tidak akan ada artinya, karena ternyata sang Penerbang belum tentu sehat selama kurun waktu 6 bulan dari penerbitan Sertifikat Kesehatan itu. Sehingga bila terjadi sesuatu yang tak diinginkan pada pesawat dan penumpang yang dipercayakan padanya, sedangkan Pilot atau Penerbang diketahui mempunyai penyakit kronis (meski terkontrol) biasanya tudingan kausa yang pertama akan jatuh pada kondisi kesehatan sang Pilot. Itulah sebabnya perlu meninjau secara yuridis Sertifikat Kesehatan penerbang sipil di Indonesia.

Sertifikat Kesehatan Penerbang Sipil di Indonesia dikeluarkan berdasarkan Keputusan Direktur Jendral Perhubungan Udara Nomor: Skep/62/V/2004 tanggal 28 Mei 2004 tentang Sertifikat Kesehatan Personil Penerbangan.

Peraturan Pemerintah RI No 3 tahun 2001 tentang Keamanan dan Keselamatan Penerbangan

Keputusan Menteri Perhubungan dan Telekomunikasi RI Nomor : KM 75 tahun 2000 tanggal 9 Nopember 2000 tentang Civil Aviation Safety Regulation Part 67, Medical Standards and Certification 
Adapun jenis sertifikat kesehatan yang dimaksud, diklasifikasikan dalam³:

a. Sertifikat Kesehatan Kelas Satu, diberikan kepada :

1. Airline Transport Pilot

2. Commercial Pilot

3. Flight Navigator

b. Sertifikat Kesehatan kelas Dua, diberikan kepada :

1. Flight Engineering

2. Air Traffic Control

3. Flight Attendant

4. Private Pilot

5. Student Pilot

c. Sertifikat Kesehatan Kelas Tiga, diberikan kepada :

1. Flight Operation Officer

2. Basic Air Traffic Services

3. Sport Pilot

4. Flight Service Office

5. Aircraft Maintenance Engineering

6. Petugas Pelayanan Informasi Aeronautika (AIS)

7. Teknisi Elektronika Penerbangan

8. Teknisi Listrik Penerbangan

9. Petugas Pemandu Parkir Pesawat Udara

10. Petugas Pertolongan Kecelakaan Pesawat dan Pemadam Kebakaran ( PKP-PK)

11. Operator Garbarata

12. Operator Peralatan Pelayanan Darat Pesawat Udara

13. Teknisi Perawatan Kendaraan dan Peralatan PKP-PK

14. Petugas Salvage

15. Petugas Pengujian Barang dan Penumpang di Bandar Udara

16. Petugas Penanganan Pengangkutan Bahan dan/atau Barang Berbahaya dengan Pesewat Udara

Adapun masa berlaku Sertifikat Kesehatan tersebut sebagai berikut :4

a. Sertifikat Kesehatan Kelas Satu, berlaku 6 (enam) bulan.

b. Sertifikat Kesehatan Kelas Dua, berlaku untuk jangka waktu 12 (dua belas) bulan

c. Sertifikat Kesehatan Kelas Tiga, berlaku untuk jangka waktu 12 (dua belas) bulan, atau berdasarkan recurrent atau rating sebagaimana diatur dalam sertifikat kecakapan.

Penulis membatasi pembahasan ini pada Penerbang Sipil Airline Transport Pilot yang mempunyai Sertifikat Kesehatan kelas satu, lebih khusus lagi yaitu pada Penerbang yang membawa pesawat penumpang komersial, dimana Sertifikat Kesehatannya berlaku untuk 6 bulan.

Pokok permasalahan pada Sertifikat Kesehatan Penerbang sipil di Indonesia adalah : "Apakah secara yuridis Sertifikat Kesehatan dapat melindungi Penerbang sipil di Indonesia dari tuntutan hukum bila terjadi insiden atau accident dalam menjalankan tugas? "

3 Ibid

4 Ibid 
Dengan melihat pokok permasalahan diatas maka dapat diidentifikasi beberapa persoalan sebagai berikut:

a. Sejauh mana Regulasi yang ada di Indonesia berperan dalam fungsi pengawasan bagi Penerbang dalam memperoleh Sertifikat Kesehatan?

b. Bagaimana keabsahan Sertifikat Kesehatan Penerbang Sipil di Indonesia yang berlaku untuk enam bulan dapat memberi jaminan, bahwa dalam kurun waktu 6 bulan tersebut Penerbang masih dalam kondisi siap terbang?

c. Bagaimana Sertifikat Kesehatan dapat berfungsi sebagai payung hukum bagi Penerbang yang mendapatkan medical Flexibility?

Metode pendekatan yang dipergunakan dalam penelitian ini adalah metode pendekatan yuridis normatif, yaitu suatu cara meneliti dalam penelitian hukum yang dilakukan terhadap bahan pustaka atau data sekunder belaka dan dengan menggunakan metode berpikir deduktif serta kriterium kebenaran koheren ${ }^{5}$.

\section{HASIL PENELITIAN dan PEMBAHASAN}

\section{A Regulasi bidang Keselamatan Penerbangan tentang fungsi pengawasan memperoleh Sertifikat kesehatan dan penerapannya}

Awal regulasi ini dimulai ketika diadakan Konvensi di Chicago pada tahun 1944. Konvensi yang kemudian dinamakan sesuai dengan lokasi diadakannya, yaitu Chicago Convention, diikuti oleh 52 negara dan menghasilkan The Convention of International Civil Aviation. Saat ini anggotanya berjumlah 189 negara termasuk Indonesia, yang telah menjadi anggota Dewan sejak 1962 sampai 2001, kemudian menjadi anggota biasa sampai sekarang. Sehingga Indonesia, sebagai salah satu negara yang telah meratifikasi hasil Konvensi tersebut, harus mengikuti keputusan bersama dari Konvensi ini, termasuk di dalamnya masalah Sertifikat Kesehatan bagi Penerbang ${ }^{6}$. Regulasi ini bukan saja memberikan keamanan pada penerbang dan maskapai penerbangan, tapi juga pada masyarakat.

\section{a. Regulasi Yang berlaku secara Internasional}

Dalam International Civil Aviation Organization (ICAO), ada beberapa hal yang berkaitan dengan kesehatan Penerbang dan Keselamatan Penerbangan adalah sebagai berikut :

\section{ICAO ANNEX 1: PERSONNEL LICENSING \\ CHAPTER 1. General Rules}

1.2.4, Evidence of Medical Fitness

1.2.4.1 the Licensing Authority issues the licence holder with the appropriate Medical Assessment,

1.2.4.2 The period of validity of Medical Assessment shall be in accordance with 1.2.5.2

1.2.5.2, Validity of Medical Assessment

Private Pilot License: 60 months

Commercial Pilot License: 12 months

Airline Transport Pilot License: 12 months

Flight Navigator: 12 months

Flight Engineer: 12 months

5 Wila Chandrawila Supriadi, Metode Penelitian (tidak dipublikasikan) dalam Materi Kuliah "Metode Penelitian Hukum" Program Pascasarjana Program Studi Magister Hukum Kesehatan Unika Soegijapranata, Semarang, 2006, hlm. 8; Lihat pula Soerjono Soekanto \& Sri Mamudji, Penelitian Hukum Normatif (Suatu Tinjauan Singkat), Rajawali Pers, Jakarta, 2001, hlm. 13-14; Lihat pula Burhan Ashshofa, Metode Penelitian Hukum, Rineka Cipta, Jakarta, 1998, hlm.35-37.

6 Evans, Anthony D.B., International Regulation of Medical Standards, in Ernsting's Aviation Medicine $4^{\text {th }}$ ed., Edward Arnold (Publishers) Ltd, 2006, p.549 
Air Traffic Controller: 48 months

1.2.5.2.2 ATPL holder engages in single-crew, commercial, pax. carrying operations who passed his $40^{\text {th }}$ birthday, shall have his medical validity reduced to 6 months.

1.2.5.2.3 ATPL holder engages in commercial operations who passed his $60^{\text {th }}$ birthday, shall have his medical validity reduced to 6 months

1.2.4.3 Flight crew and ATC shall not exercise their privileges unless they hold a current, appropriate medical assessment

1.2.4.4 Contracting States shall designate medical examiners to conduct medical examination...

CHAPTER 2. Licences and Ratings for Pilots

2.2, Student Pilot

2.2.3, Medical Fitness: Class 2

2.3, Private Pilot License

2.3.1.4, Medical Fitness: Class 2

2.4, Commercial Pilot License

2.4.1.4, Medical Fitness: Class 1

2.6, Airline Transport Pilot License

2.6.1.4, Medical Fitness: Class 1

CHAPTER 6. Medical Provisions for Licensing

Note 1. - The Standards and Recommended Practices

established in this chapter cannot, on their own, be sufficiently detailed to cover all possible individual situations. Of necessity, many decisions relating to the evaluation of medical fitness must be left to the judgement of the individual medical examiner. The evaluation must, therefore, be based on a medical examination conducted throughout in accordance with the highest standards of medical practice.

Note 2.- Predisposing factors for disease, such as obesity and smoking, may be important for determining whether further evaluation or investigation is necessary in an individual case.

Note 3. - In cases where the applicant does not fully meet the medical requirements and in complicated and unusual cases, the evaluation may have to be deferred and the case submitted to the medical assessor of the Licensing Authority for final evaluation. In such cases due regard must be given to the privileges granted by the licence applied for or held by the applicant for the Medical Assessment, and the conditions under which the licence holder is going to exercise those privileges in carrying out assigned duties.

Sebagai anggota ICAO, Indonesia telah melakukan beberapa hal seperti di bawah ini :

1. Membuat peraturan keselamatan penerbangan sipil Indonesia yang sesuai dengan Standard and Recommended Practices pada ICAO Annexes (di antaranya Annex 1, 6, 8, 14)

2. Memastikan bahwa sarana dan prasarana penerbangan sipil, pelaku-pelaku kegiatan penerbangan sipil, organisasi maupun personil individu memenuhi peraturan tersebut; dan

3. Melakukan pengawasan dan penegakan hukum untuk memastikan bahwa butir-butir (b) tetap dipenuhi selama pengoperasian dan menjalankan kegiatannya.

b. Regulasi Yang berlaku di Indonesia

Di Indonesia beberapa regulasi yang terkait sebagai berikut :

1. Undang Undang RI No. 1 / Tahun 2009 tentang Penerbangan

Dalam Undang Undang RI No.1/ Tahun 2009 Tentang Penerbangan ini, beberapa hal yang perlu diperhatikan karena berkaitan langsung dengan Kesehatan Penerbangan, adalah sebagai berikut, Pasal 59 ayat 1, Personel penerbangan yang telah memiliki lisensi wajib: 
melaksanakan pekerjaan sesuai dengan ketentuan di bidangnya (a), mempertahankan kemampuan yang dimiliki (b); dan melakukan pemeriksaan kesehatan secara berkala (c).

\section{PP Nomor 3 Tahun 2001 Tentang Keamanan dan keselamatan penerbangan}

Beberapa isi dari Peraturan Pemerintah Nomor 3 Tahun 2001 tentang Keamanan dan Keselamatan Penerbangan yang berkaitan dengan Kesehatan Penerbangan cukup detail dalam pasal dan ayat ayatnya sehingga tidak perlu penjelasan lagi.

Pasal 79

(1) Personil penerbangan yang telah memiliki sertifikat kecakapan diwajibkan:

a. mematuhi ketentuan sesuai dengan sertifikat kecakapan yang dimiliki;

b. mempertahankan kecakapan dan kemampuan yang dimiliki;

c. mematuhi ketentuan pemeriksaan kesehatan secara berkala.

(2) Personil penerbangan yang akan melaksanakan tugas diwajibkan :

a. memiliki sertifikat sesuai dengan tugas yang akan dilaksanakan;

b. dalam keadaan kondisi sehat jasmani dan rohani;

c. cakap dan mampu untuk melaksanakan tugas.

(3) Personil penerbangan selama melaksanakan tugas diwajibkan mematuhi seluruh ketentuan peraturan keamanan dan keselamatan penerbangan.

(4) Ketentuan lebih lanjut mengenai kewajiban personil penerbangan sebagaimana dimaksud dalam ayat (1), diatur dengan Keputusan Menteri.

Pasal 87

(1) Pelayanan kesehatan penerbangan diselenggarakan oleh Pemerintah dan pelaksanaannya dapat dilimpahkan kepada badan hukum Indonesia atau perorangan yang mempunyai kualifikasi kesehatan penerbangan.

(2) Pelayanan kesehatan penerbangan sebagaimana dimaksud dalam ayat (1) meliputi kegiatan :

a. pengujian dan / atau pemeliharaan kesehatan terhadap :

1) personil operasi pesawat udara;

2) personil penunjang operasi pesawat udara;

3) personil pelayanan navigasi penerbangan;

4) personil pelayanan pengoperasian bandar udara;

5) personil pelayanan keamanan dan keselamatan perusahaan angkutan udara.

b. pemeriksaan higiene dan sanitasi bandar udara, fasilitas bandar udara, kesehatan dan keselamatan kerja fasilitas penunjang penerbangan.

c. pemeriksaan higiene dan sanitasi pesawat udara.

3. Keputusan Menteri Perhubungan dan Telekomunikasi No. KM.75 Tahun 2000 Tentang Civil Aviation Safety Regulation (CASR) Part 67, Medical Standards and Certification

Dalam Civil Aviation Safety Regulations (CASR) 67, Standar Kesehatan \& Sertifikasi Kesehatan bagi personel penerbangan RI, ditetapkan berdasarkan KM 75 tahun 2000. Isi dari regulasi ini adalah persyaratan-persyaratan dan prosedur pengujian kesehatan sebelum mengeluarkan sertifikat kesehatan bagi personil penerbangan di Indonesia. Pusat Kesehatan Penerbangan Sipil di Indonesia (PKPS), yang berada di bawah Direktorat Jendral perhubungan udara, telah memiliki Certificate of Medical untuk pemeriksaan kesehatan personel penerbangan sesuai standar yang ditetapkan dalam CASR (Civil Aviation Safety Regulation) Part 67. Sertifikat ini diterima dan berlaku di seluruh negara anggota ICAO. 
Regulasi yang mengatur seleksi Penerbang di Indonesia, baik tata cara pemeriksaan maupun kriteria peserta tes yang memenuhi syarat, telah diterbitkan Keputusan Menteri Perhubungan dan Telekomunikasi RI Nomor : KM 75 tahun 2000 tanggal 9 Nopember 2000 tentang Civil Aviation Safety Regulation (CASR) Part 67, Medical Standards and Certification. Sedangkan tata cara mendapatkan Sertifikat Kesehatan bagi Penerbang sesuai dengan klasifikasi Penerbang tersebut serta lama berlakunya diatur dalam Keputusan Direktur Jendral Perhubungan Udara Nomor: SKEP/62/V/2004 tentang Sertifikat Kesehatan Personil Penerbangan.

Seseorang yang telah menjadi Penerbang maka ia harus memelihara kesehatannya secara jasmani dan rohani serta harus memeriksakan kesehatannya secara berkala seperti yang diundangkan dalam UU RI nomor 1 tahun 2009 tentang penerbangan pasal 59 (1) dan Peraturan Pemerintah nomor 3 tahun 2001 tentang Keamanan dan Keselamatan Penerbangan pasal 79 (1). Namun untuk kasus medical flexibility, masih mengadop dari ICAO yaitu dari Dokumen 8984-AN/895 Annex 1: Personnel Licensing, Chapter I, 1.2.4.8., karena penerbangan sipil di Indonesia belum mempunyai aturan tersendiri. Demikianpun dengan tim penilai atau medical assessor dan konsultan pakar atau Aeromedical Consultation Service (ACS), karena pernyataan dalam PP nomor 3 tahun 2001 pasal 87(1): Pelayanan kesehatan penerbangan diselenggarakan oleh Pemerintah dan pelaksanaannya dapat dilimpahkan kepada badan hukum Indonesia atau perorangan yang mempunyai kualifikasi kesehatan penerbangan. Ayat 1 dalam pasal 87 ini hanya menuju pada Pusat Kesehatan Penerbangan Sipil dan dokter penerbangan. Keputusan kasus medical flexibility adalah hasil kajian suatu tim yaitu Aeromedical Consultation Service/ACS yang diminta oleh Medical Assessor. Jadi selain Medical Assessor juga perlu adanya penetapan personil yang dapat diundangkan sebagai ACS dari berbagai disiplin ilmu dan latar belakang Kedokteran penerbangan.

B. Langkah langkah yang diambil agar Sertifikat Kesehatan Penerbang Sipil di Indonesia yang berlaku 6 bulan ke depan, benar benar dapat terjaga keabsahannya

Secara internasional, ada 2 cara untuk memeriksa Penerbang sebelum menerbitkan Sertifikat Kesehatan. Yang pertama adalah tersentralisir, yaitu Penerbang datang kesatu tempat saja dimana semua peralatan pemeriksaan dan SDM nya terkonsentrasi. Penerbang diperiksa disini, bahkan bila terdapat gangguan juga diobati disini. Sehingga tempat ini biasanya ada kaitannya dengan Rumah Sakit. Pemeriksaan dapat dilakukan oleh tenaga medis militer atau sipil yang mempunyai kualifikasi sebagai dokter penerbangan (Flight Surgeon). Sedangkan cara kedua yaitu desentralisasi, dimana pemilik otoritas mempunyai jaringan Medical Examiner lain yang berkualifikasi dokter penerbangan, dan Penerbang membawa hasil pemeriksaan dari jaringan yang telah ditunjuk ini untuk kemudian Sertifikat Kesehatannya akan diterbitkan oleh pemilik otoritas ${ }^{7}$.

Fungsi pemilik otoritas secara internasional adalah terus mengikuti, mencatat, dan menjaga kondisi kesehatan Penerbang. Boleh dikatakan sebagai fungsi pengawasan. Termasuk juga bila hal ini berhubungan dengan asuransi ${ }^{8}$. berikut ${ }^{9}$ :

Di Indonesia, tugas dan fungsi Pusat Kesehatan Penerbangan Sipil adalah sebagai

7 Evans, Anthony D.B., International Regulation of Medical Standards, in Ernsting's Aviation Medicine $4^{\text {th }}$ ed., Edward Arnold (Publishers) Ltd, 2006, p.562.

8 Ibid.

9 Keputusan Menteri Perhubungan Nomor: SK 38/OT 002/ Phb-83 tentang Organisasi dan Tata Kerja Balai Kesehatan Penerbangan Direktorat Jendral Perhubungan Udara 
Tugas : "Melaksanakan pemeriksaan dan pengujian kesehatan personil penerbangan dan pemeliharaan kesehatan, hygiene dan sanitasi di Bandar Udara dan pesawat udara dengan melakukan penelitian di laboratorium".

Sedangkan fungsinya yaitu, menyusun rencana dan program serta melaksanakan perawatan dan bimbingan kegiatan Pusat Kesehatan Penerbangan Sipil; Melaksanakan kegiatan fungsional di bidang pemeriksaan, pengujian dan pemeliharaan secara medis personil penerbangan beserta sarananya, higiene dan sanitasi di bandar udara dan pesawat udara; Melakukan urusan tata usaha Pusat Kesehatan Penerbangan Sipil.

Melihat dari tugas dan fungsi tersebut, mengindikasikan bahwa semua penerbang sipil harus diperiksa dan dimonitor kesehatannya, sama seperti kegiatan dari pemegang otoritas Sertifikat Kesehatan di dunia internasional yang tersentralisir. Fungsi yang tercantum di atas menunjukkan bahwa kegiatan penerbangan merupakan suatu sistem yang tak dapat dipisahkan satu dengan lainnya termasuk dengan lingkungannya, masalah higiene dan sanitasinya, baik di dalam pesawat terbang maupun di bandar udara mendapat perhatian yang sama. Tugas dan fungsi Pusat Kesehatan Penerbangan Sipil sejauh ini sangat luas dan kompleks. Bila dibandingkan kondisi SDM yang ada disini, yaitu tahun 2009: 4 dokter spesialis, 14 dokter umum, 6 dokter gigi, 20 paramedis, 2 penunjang teknis, dan direncanakan tambahan pada tahun 2010: 8 tenaga medis dan 6 paramedis (Sumber: Balai Hatpen tahun 2009). Jumlah ini tidaklah sebanding dengan beban tugas dan fungsinya, dengan demikian perlu membagi sebagian fungsi pengawasan yang dapat didelegasikan pada dokter penerbangan(Flight Surgeon) dari maskapai penerbangan yang bersangkutan, sesuai dengan Pasal 87 (1)Pelayanan kesehatan penerbangan diselenggarakan oleh Pemerintah dan pelaksanaannya dapat dilimpahkan kepada badan hukum Indonesia atau perorangan yang mempunyai kualifikasi kesehatan penerbangan.

Status Sertifikat Kesehatan bagi yang menurun kesehatannya seperti yang tertuang dalam Document 8984-AN/895 Part I, Chapter I, Manual of Civil Aviation Medicine dari ICAO 1.2.6.1 disebutkan :

Decrease in medical fitness

1.2.6.1 Holders of licences provided for in this Annex shall not exercise the privileges of their licences and related ratings at any time when they are aware of any decrease in their medical fitness which might render them unable to safely and properly exercise these privileges.

1.2.6.1.1 Recommendation. - Licence holders should inform the Licensing Authority of confirmed pregnancy or any decrease in medical fitness of a duration of more than 20 days or ICAO Preliminary Unedited Version - July 2008 I-1-11 which requires continued treatment with prescribed medication or which has required hospital treatment.

1.2.6.1.2 Recommendation. - Each Contracting State should, as far as practicable, ensure that licence holders do not exercise the privileges of their licences and related ratings during any period in which their medical fitness has, from any cause, decreased to an extent that would have prevented the issue or renewal of their Medical Assessment.

The provisions of Annex 1, 1.2.6.1, would apply if there is a decrease in medical fitness attributable to the effects of intercurrent disease, injury, alcohol or other psychoactive substances, medication, fatigue, sleep disturbances due to time zone changes, adverse climatic conditions and disrupted regular work/rest schedules which might render the holder of a licence or rating incapable of meeting the medical requirements of his licence or rating.

Jadi keluhan kesehatan yang menurun harus segera dilaporkan untuk menjadi perhatian dari pemilik otoritas. Keadaan tubuh yang tidak fit bila tidak dlaporkan akan menjadi suatu keadaan yang membahayakan. Bila terjadi kecelakaan dan terbukti bahwa Penerbang saat itu dalam kondisi unfit, maka ini merupakan pelanggaran karena menyalahi aturan dalam ICAO Document 8984- AN/895 Annex 1, Personnel Licensing, Chapter I, 1.2.6.1., dan PP Nomor 3 Tahun 2001 Tentang Keamanan dan Keselamatan Penerbangan Pasal 79 (2) 
Personil penerbangan yang akan melaksanakan tugas diwajibkan: memiliki sertifikat sesuai dengan tugas yang akan dilaksanakan (a); dalam keadaan kondisi sehat jasmani dan rohani (b); cakap dan mampu untuk melaksanakan tugas (c).

Jadi keluhan kesehatan yang menurun harus segera dilaporkan untuk menjadi perhatian dari pemilik otoritas. Hal ini harus ditindaklanjuti sampai tuntas sehingga tidak mengorbankan keamanan dan keselamatan penerbangan. Tindak lanjut dapat berupa istirahat, rawat jalan, konsul ke rumah sakit / spesialis terkait sampai larangan terbang atau grounded.

Bila melihat yang dilakukan di TNI AU, Dokter Penerbangan pada setiap Skadron Udara mempunyai tugas :

a. Administrasi awak pesawat.

b. Rekording kesehatan awak pesawat, meliputi perencanaan, pelaksanaan dan tindak lanjut kelainan rikkesla/ILA yang ditemukan dari awak pesawat.

c. Melaksanakan Pre Flight Check / PFC awak pesawat.

d. Mencatat hasil Pre Flight Check pada buku dan buku saku awak pesawat serta mengisi formulir PFC.

e. Mengatur jadwal awak pesawat untuk pemeriksaan kesehatan berkala atau Indoktrinasi dan Latihan Aerofisiologi (ILA).

f. Memonitor secara ketat:

1. Kesehatan fisik.

2. Kesehatan jiwa.

3. Kesamaptaan jasmani.

4. Keadaan gizi awak pesawat.

g. Sebagai Perwira K3 (Keselamatan dan Kesehatan Kerja) di Skadron Udara melakukan supervisi di titik bekal/teknik Skadron Udara.

h. Mengatur penyediaan obat untuk P3K di Skadron Udara dan di pesawat.

i. Sebagai konsultan kesehatan dan kesehatan penerbangan bagi anggota Skadron Udara dan awak pesawat.

j. Mengirim awak pesawat yang sakit ke Rumah Sakit dan menindaklanjuti hasil pemeriksaan kesehatan berkala/Indoktrinasi dan Latihan Aerofisiologi awak pesawat di Klinik awak pesawat.

k. Membuat laporan bulanan kesehatan awak pesawat tembusan ke Kadiskes Koopsau dan ke Klinik awak pesawat di Rumah Sakit.

Pre Flight Check yang dilaksanakan pada setiap Penerbang sebelum melaksanakan tugas terbang pada hari itu mencakup pemeriksaan tanda vital, yaitu tekanan darah, denyut nadi dan pernapasan per menit. Sedangkan kondisi yang dirasakan oleh penerbang dituangkan dalam bentuk checklist yang harus diisi secara jujur, seperti di bawah ini :

a. Apakah ada keluhan tentang kesehatan pusing, mengantuk, batuk, pilek, panas dan lain lain.

b. Apakah kurang tidur pada $2-3$ hari terakhir, terutama tadi malam?

c. Apakah belum makan pagi ?

d. Apakah minum obat obat tertentu, banyak merokok, kopi, alkohol dan lain lain ?

e. Apakah mengalami tekanan mental, ataupun trauma psikis, tidak dapat konsentrasi, memikirkan sesuatu?

f. Apakah ada masalah keluarga?

g. Apakah penerbangan hari ini melebihi yang sudah ditentukan?

h. Apakah awak pesawat menjalani grounded sebelumnya dan berapa lama? 
i. Apakah waktu pemeriksaan berkala / Indoktrinasi dan Latihan aerofisiologi telah terlewat / terlambat?

Dengan uraian tugas ini maka setiap Penerbang yang akan melaksanakan tugas terbangnya hari itu termonitor kesehatannya. Dan semua remark yang ditemukan pada waktu pemeriksaan berkala segera ditindaklanjuti sampai kondisi Penerbang memungkinkan untuk terbang kembali sesuai dengan motto Kedokteran Penerbangan yaitu Keep Them Flying. Namun untuk penerbangan sipil dengan jadwal penerbangan yang demikian ketat dan jumlah besar, maka kegiatan pengawasan seperti ini tidak memungkinkan. Masalah ada pada pengerahan jumlah yang besar Flight Surgeon dan Flight Nurse itupun belum tentu akan terlayani semuanya karena jadwal yang ketat, sehingga kegiatan ini tidak efisien.

Di Australia, dokter penerbangan dan Aviation Medical Offficer (AVMO) tidak setiap hari dapat memperhatikan para Penerbang. Diharapkan para Penerbang sendiri yang memutuskan apakah fit ataukah unfit untuk melaksanakan tugas terbang. Untuk itu diberikan suatu checklist dengan mnemonic l'M SAFE, yaitu sbb ${ }^{10}$ :

I lilness. Am I Illness? Do I feel sick in any way?

M Medication. I take drugs: will they impair my thinking, judgement or performance?

$S$ Stress. Am I mentally fit? Can I devote my full attention to flying?

A Alcohol. When did I drink the last drink?

F Fatigued. Am I physically fatigued? Am I too tired to give 100 per cent?

E Eating. Am I huyngry? Did I eat too much? Do I have indigestion?

Mnemonic sederhana ini dapat membantu setiap Penerbang untuk mengingat apa yang terjadi pada dirinya agar tidak berisiko terhadap keselamatan penerbangan.

Seperti halnya di Australia, di Indonesia regulasi sudah cukup jelas, namun perbedaannya ada pada budaya keamanan dan keselamatan terbang yang belum tumbuh subur. Contoh di awal tulisan ini merupakan contoh yang jelas bahwa seorang Penerbang melupakan kewajibannya untuk mengatakan bahwa ia tidak dapat melaksanankan tugas terbang dengan alasan kesehatan. Penerbang pada contoh ini telah menyalahi aturan dalam ICAO Document 8984- AN/895 Annex 1, Personnel Licensing, Chapter I, 1.2.4.8, dan PP Nomor 3 Tahun 2001 Tentang Keamanan dan Keselamatan Penerbangan khususnya Pasal 79. Dan dari kasus ini terlihat bahwa keabsahan Sertifikat Kesehatan Penerbang yang berlaku 6 bulan belum sepenuhnya dapat dipertanggungjawabkan.

Penerbangan sipil di Indonesia, bila tidak memungkinkan menjalankan mekanisme yang ada di TNI AU, sebaiknya mengadakan kombinasi dari sebagian yang telah dilaksanakan di TNI AU dan di Australia. Penentuan fit dan unfit sebelum melaksanakan tugas terbang setiap harinya dibuat oleh setiap Penerbang dengan mengisi dan menandatangani checklist pre flight check yang tersedia dan menyerahkan kepada petugas penerbangan sewaktu mengisi flight plan. Dalam checklist tersebut selain berisi pertanyaan seputar kesehatannya (mnemonic l'M SAFE), juga berisi peringatan akan sanksi bila tidak mematuhi regulasi keamanan dan keselamatan terbang. Pada waktu tertentu dapat dilakukan uji petik untuk melihat secara langsung kondisi Penerbang yang bertugas saat itu.

Dengan adanya fungsi pengawasan seperti ini maka Sertifikat Kesehatan Penerbang Sipil di Indonesia yang berlaku 6 bulan ke depan, akan terjaga keabsahannya serta budaya keamanan dan keselamatan terbang secara perlahan akan tumbuh.

10 Don't Let your Lifestyle Be The Death Of You, Australian Defence Force (ADF) by the Directorate of Defence Aviation and Air Force Safety (DDAAFS), in Aviation Safety Spotlight 01 2010, p.10-15. 


\section{Regulasi bagi Penerbang yang mendapatkan medical flexibility}

Salah satu yang penting untuk dimonitor adalah Penerbang dengan status medical Flexibility, yaitu kondisi Penerbang yang tidak sesuai standar kesehatan yang disyaratkan namun karena kemampuan, keahlian dan pengalamannya maka selama hal ini tidak mengorbankan keselamatan penerbangan maka Penerbang tersebut dapat melaksanakan tugas terbang dengan catatan adanya medical flexibility ${ }^{11}$.

Keputusan mendapatkan medical flexibility adalah wewenang dari Tim Aeromedical Consultation Service (ACS) atas permintaan medical assessor ketika sulit mendapatkan kesimpulan dari hasil pemeriksaannya ${ }^{12}$. Kasus medical flexibility berbeda dengan kasus inkapasitasi, dimana Inkapasitasi, didefinisikan sebagai penurunan kondisi kesehatan sedemikian yang tak dapat diprediksi tapi sangat membahayakan keamanan dan keselamatan penerbangan ${ }^{13}$. Banyak bentuk inkapasitasi mulai dari meninggal mendadak sampai bentuk yang sulit dideteksi ketika terjadinya kehilangan fungsi yang dapat terjadi dalam segala umur dan segala fase dalam penerbangan sehingga untuk memonitor terjadinya agak sulit. Sedangkan pada kasus medical flexibility, sejak keputusan disampaikan oleh ACS kepada medical assessor, saat itu juga perhatian harus difokuskan sesuai yang tercantum dalam rekomendasi aeromedis agar dapat menghindari insiden apalagi kecelakaan.

Di lingkungan TNI AU, kondisi medical flexibility hamper mirip dengan waiver atau perkecualian. Yang dapat mengeluarkan pernyataan waiver hanyalah Kepala Staf Angkatan Udara. Sedangkan saran waiver disampaikan setelah rapat para pakar yang disebut rapat BPKP (Badan Penentu Kesehatan Personil). Bila seorang Penerbang diperbolehkan terbang dengan status waiver, maka dokter skadron udara, yang adalah dokter penerbangan (Flight Surgeon) akan memonitor sesuai saran dari hasil rapat BPKP tersebut. Pendampingan ini akan terus dilaksanakan sampai pemeriksaan kesehatan berkala berikutnya.

Di lingkungan penerbangan sipil dimana fungsi pendampingan dokter penerbangan belum memungkinkan karena keterbatasan SDM, maka mekanisme pengawasan terhadap Penerbang dengan kasus medical flexibility harus lebih ketat dari biasanya. Penerbang tersebut selain mengisi checklist, ia dijadwalkan secara tetap untuk memeriksakan kekurangannya dan melaporkan pada dokter penerbangan. Contoh pada Penerbang dengan kasus DM (Diabetes mellitus - kencing manis), dalam keadaan gula darah yang terkontrol dan yang bersangkutan patuh menjaganya, maka ia dinyatakan laik untuk melaksanakan tugas terbang. Selanjutnya, untuk pasien seperti ini di lingkungan TNI AU, sebulan sekali dimonitor kadar gula darah dan $\mathrm{Hb}$ A1c nya. Kasus medical flexibility merupakan keadaan khusus, masalah ini belum ada aturan tersendiri dan masih mengadop dari ICAO. Kasus ini tidak dapat diputuskan oleh medical assessor karena itu harus dibawa dalam suatu rapat tim kesehatan yang terdiri dari para pakar kedokteran penerbangan yang sesuai dengan bidangnya, yang disebut Aeromedical Consultation Service (ACS). Tim ini seharusnya dibentuk secara tetap dan mendapatkan legalitas dari Menteri Perhubungan agar hasil keputusan tim ini mempunyai kekuatan hukum. Kondisi medical flexibility menuntut kepatuhan Penerbang dan fungsi pengawasan dan evaluasi secara tetap oleh dokter penerbangan sesuai rekomendasi tim ACS. Bila ini telah dilaksanakan, maka kasus seperti contoh di depan tidak akan terjadi di lapangan. Dalam hal ini fungsi pendampingan dari dokter penerbangan (Flight Surgeon) sangat penting dan dibutuhkan pendelegasian wewenang dari Pusat Kesehatan Penerbangan Sipil kepada dokter penerbangan dari perusahaan penerbangan yang bersangkutan, untuk kemudian secara aktif membantu Pusat Kesehatan Penerbangan Sipil melaksanakan fungsi tersebut.

ICAO, Manual of Civil Aviation Medicine, July 2008, p.I-1-8

ICAO, Manual of Civil Aviation Medicine, July 2008, p.I-1-15

ICAO, Manual of Civil Aviation Medicine, Doc 8984-AN/895, Part I, Chapter 3, pl-3-1, 2008 


\section{KESIMPULAN dan SARAN}

\section{A. Kesimpulan}

Dari uraian di atas ini, beberapa hal yang dapat ditarik sebagai kesimpulan dari pembahasan Tinjauan Yuridis Sertifikat Kesehatan Sebagai Perlindungan Hukum bagi Penerbang Sipil di Indonesia, adalah sebagai berikut :

a. Regulasi bidang Keselamatan penerbangan yang berlaku di Indonesia tentang fungsi pengawasan memperoleh Sertifikat Kesehatan, khususnya pada Penerbang Sipil Airline Transport Pilot (Sertifikat Kesehatan kelas satu), lebih khusus lagi yaitu pada Penerbang yang membawa pesawat penumpang komersial, telah dibuat peraturan keselamatan penerbangan sipil Indonesia yang sesuai dengan standar ICAO. Aturan yang dimaksud ada dalam Keputusan Direktur Jendral Perhubungan Udara Nomor: SKEP/62/V/2004 tentang Sertifikat Kesehatan Personil Penerbangan

b. Langkah langkah yang diambil agar Sertifikat Kesehatan Penerbang Sipil di Indonesia yang berlaku 6 bulan ke depan, belum ada, baik aturannya, mekanismenya bahkan SDM belum memadai secara kualitas dan kuantitas. Sehingga sertifikat tersebut belum dapat terjaga keabsahannya.

c. Penerbang yang mendapatkan medical flexibility harus dilindungi statusnya dengan Surat keputusan Menteri bagi Tim penilai kesehatan (Medical Asessor) dan Tim Pakar kesehatan Penerbangan (Aeromedical Consultation Service) yang merekomendasi kasus ini. Penerbang tersebut selain mengisi checklist, ia dijadwalkan secara tetap untuk memeriksakan kekurangannya dan melaporkan pada dokter penerbangan

\section{B. Saran}

a. Mengusulkan kepada Menteri Perhubungan melalui Dirjen Perhubungan Udara agar mengeluarkan keputusan tentang tata kerja menjamin keabsahan Sertifikat Kesehatan Penerbang Sipil di Indonesia sejak diterbitkan sampai pemeriksaan berkala berikutnya. Mekanisme yang disarankan sebagai berikut : Penentuan fit dan unfit sebelum melaksanakan tugas terbang setiap harinya dibuat oleh setiap Penerbang dengan mengisi dan menandatangani checklist pre fllight medical check yang tersedia dan menyerahkan kepada petugas penerbangan sewaktu mengisi flight plan. Dalam checklist tersebut selain berisi pertanyaan seputar kesehatannya juga berisi peringatan dan sanksi bila tidak memenuhi regulasi keamanan dan kreselamatan terbang. Pada waktu tertentu dilakukan uji petik untuk melihat secara langsung kondisi Penerbang yang bertugas saat itu.

b. Mengusulkan kepada Menteri Perhubungan melalui Dirjen Perhubungan Udara agar menambah personil fungsional pada Pusat Kesehatan Penerbangan Sipil sehingga dapat melaksanakan tugas dan fungsinya sesuai Keputusan Menhub no. SK 38/OT 002/Phb.83 tentang organisasi dan tata kerja Balai Kesehatan Penerbangan Dirjen Perhubungan Udara. Dan agar setiap operator penerbangan harus mempunyai dokter penerbangan untuk menerimapendelegasian wewenang dalam pengawasan Penerbang di lapangan termasuk kasus medical flexibility.

c. Mengusulkan kepada Menteri Perhubungan melalui Dirjen Perhubungan Udara agar menerbitkan Surat Keputusan Menteri untuk jabatan Medical Asessor, dan Aeromedical Consultation Service, yang berisi fungsi dan wewenangnya serta pengawakannya agar Penerbang yang mendapatkan medical flexibility terlindungi statusnya. 


\section{DAFTAR KEPUSTAKAAN}

\section{Buku :}

A. Widanti S., Prof. Dr.,SH.,CN., Petunjuk Penulisan Usulan Penelitian dan Tesis, Prodi Magister Hukum Unika Soegijapranata, Semarang, 2009

Evans, Anthony D.B., International Regulation of Medical Standards, in Ernsting's Aviation Medicine $4^{\text {th }}$ ed., Edward Arnold (Publishers) Ltd, 2006.

Orford, Robert R., and Silberman, Warren S., Pilot Health and Aeromedical Certification, in Fundamentals of Aerospace Medicine $4^{\text {th }}$ ed., editors Davis,Jeffrey R., et al, Lippincott Williams and Wilkins, 2008.

Pearson R., The Concept of Aeromedical Fitness, Joint Aviation Authorities Manual of Civil Aviation Medicine, Global Engineering Documents.

Soetandyo Wignjosoebroto, Hukum (Paradigma Metode dan Dinamika Masalahnya) Editor Ifdhal Kasim et.al., Elsam dan Huma, Jakarta, 2002, hlm. 147-160.

Moh. Nazir, Metode Penelitian, Ghalia Indonesia, Jakarta, 1985, hlm. 63, 72, 405, 406 \& 427; Lihat pula Hilman Hadikusuma, Metode Pembuatan Kertas Kerja atau Skripsi Ilmu Hukum, Mandar Maju, Bandung, 1995, hlm. 98

Johnny Ibrahim, Teori dan Metodologi Penelitian Hukum Normatif, Bayumedia Publishing, Surabaya, 2006, hlm. 25-26

Koentjaraningrat, Metode-metode Penelitian Masyarakat, Gramedia, Jakarta, 1977, hlm. 16.

J. J. J. M. Wuisman, Penelitian Ilmu-ilmu Sosial (Jilid I : Asas-asas) disunting oleh : M.Hisyam, Lembaga Penerbit Fakultas Ekonomi Universitas Indonesia, Jakarta, 1996, hlm. 85-86; Lihat pula C.A. van Peursen, Susunan Ilmu Pengetahuan (Sebuah Pengantar Filsafat Ilmu) diterjemahkan oleh : J. Drost, Gramedia, Jakarta, 1993, hlm. 16.

Lihat Hilman Hadikusuma, Metode Pembuatan Kertas Kerja atau Skripsi Ilmu Hukum, Mandar Maju, Bandung, 1995, hlm. 58-61.

Fred N. Kerlinger, Asas-asas Penelitian Behavioral diterjemahkan oleh: Landung R.Simatupang, Gadjah Mada University Press, Yogyakarta, 1992, hlm. 18.

Wila Chandrawila Supriadi, Metode Penelitian (tidak dipublikasikan) dalam Materi Kuliah “Metode Penelitian Hukum” Program Pascasarjana Program Studi Magister Hukum Kesehatan Unika Soegijapranata, Semarang, 2006, hlm. 8; Lihat pula Soerjono Soekanto \& Sri Mamudji, Penelitian Hukum Normatif (Suatu Tinjauan Singkat), Rajawali Pers, Jakarta, 2001, hlm. 13-14; Lihat pula Burhan Ashshofa, Metode Penelitian Hukum, Rineka Cipta, Jakarta, 1998, hlm. 35-37.

Sedarmayanti \& Syarifudin Hidayat, MetodologiPenelitian, Mandar Maju, Bandung, 2002, hlm.23.

A. Sonny Keraf \& Mikhael Dua, Ilmu Pengetahuan (Sebuah Tinjauan Filosofis), Kanisius, Yogyakarta, 2001, hlm. 68 


\section{Undang Undang dan Peraturan Internasional dan nasional :}

International Civil Aviation Organization, Manual of Civil Aviation Medicine, Document 8984, Colorado USA, 1 November 2006.

Undang Undang RI No.1 tahun 2009 tentang Penerbangan

Peraturan Pemerintah RI No 3 tahun 2001 tentang Keamanan dan Keselamatan Penerbangan

Keputusan Menteri Perhubungan Nomor: SK 38/OT 002/ Phb-83 tentang Organisasi dan Tata Kerja Balai Kesehatan Penerbangan Direktorat Jendral Perhubungan Udara RI.

Keputusan Menteri Perhubungan dan Telekomunikasi RI Nomor : KM 75 tahun 2000 tanggal 9 Nopember 2000 tentang Civil Aviation Safety Regulation Part 67, Medical Standards and Certification

Keputusan Menteri Perhubungan Nomor : KM.39 tahun 2001 tanggal 3 Desember 2001 tentang Civil Aviation Safety Regulation, Part 183 Representatives of the DGCA

Direktur Jendral Perhubungan Udara Nomor: SKEP/62/V/2004 tentang Sertifikat Kesehatan Personil Penerbangan

Profil dan Rencana Pengembangan Pusat Kesehatan Penerbangan Sipil 2010 - 2014

Petunjuk Teknis Tentang Dukungan Kesehatan Penerbangan di Pangkalan Udara Operasi, Skep Kasau No: Skep/21/III/2001 tanggal 9 Maret 2001 